\title{
O CONSUMO DE ÁGUA NA PRODUÇÃO DE AVES, LEITE E SUÍNOS DO MUNICÍPIO DE FRANCISCO BELTRÃO - SO PR: UMA PROPOSTA DE EDUCAÇÃO AMBIENTAL NAS AULAS DE GEOGRAFIA
}

\author{
Water Consumption in Chicken, Milk and Swine Production in the Municipality of Francisco \\ Beltrão - SO PR: A Proposal for Environmental Education in Geography Lessons
}

\author{
Rosana Cristina Biral Leme* \\ Ricardo Carvalho Leme **
}

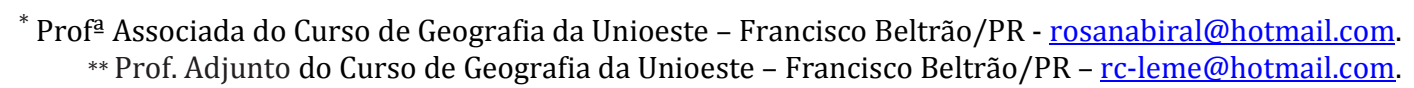

Recebido em 15/08/2018. Aceito para publicação em 25/08/2018.

Versão online publicada em 03/09/2018 (http://seer.ufrgs.br/paraonde)

\begin{abstract}
Resumo:
Pesquisas realizadas sobre o consumo de água para a produção agropecuária brasileira demonstram que tais informações são pouco acessíveis aos produtores. Da mesma forma, pesquisas sobre educação ambiental (EA) indicam que os trabalhos realizados nas escolas guardam pouca relação com os assuntos sobre a realidade local (OPOLSKY, 2015; SEGALA, 2017). Considerou-se oportuno a realização e divulgação de pesquisas sobre o consumo de água para a produção de aves, suínos e leite em Francisco Beltrão/SO-PR. Tais estimativas propiciam discernimento sobre as demandas existentes para o uso da água, além de propiciar mecanismos de questionamentos acerca da gratuidade dos recursos naturais para grandes cadeias produtivas sem que haja nenhuma contrapartida para a recuperação-conservação ambiental das pequenas propriedades das quais estes recursos são retirados, mostrando o papel socioambiental do ensino de geografia e a EA.
\end{abstract}

Palavras-chave: consumo de água; educação ambiental; ensino de geografia.

\begin{abstract}
:
Research carried out on the consumption of water for Brazilian agricultural production shows that this information is not very accessible to producers. Similarly, research on environmental education (EA) shows that the work done in schools has little relation to local reality (OPOLSKY, 2015; SEGALA, 2017). It was considered appropriate to conduct and disseminate research on water consumption for the production of poultry, pigs and milk in Francisco Beltrão / SO-PR. Such estimates provide insight into the existing demands for water use, as well as providing mechanisms for questions about the gratuitousness of natural resources for large productive chains, without there being any counterpart to the environmental conservation of the small properties from which these resources are withdrawn, Showing the socio-environmental role of geography teaching and EE.
\end{abstract}

Key-words: Water consumption; environmental education; Geography teaching.

\section{Introdução}

Dentre as questões socioambientais que abrangem povos do mundo inteiro, evidencia-se o processo de diminuição de mananciais de água potável para o abastecimento humano. Resultante da expansão do uso, da ineficácia/inexistência de tratamento do esgoto e da contaminação da água, a perda na qualidade de vida impacta milhares de pessoas no mundo inteiro (UNESCO, 2013 e 2015, REBOUÇAS, et al., 2006). Por vezes, como consequência ou em concomitância a esse déficit de água, ocorre a criação de mercado com processos produtivos e comerciais vinculados à água, transformando-a em uma mercadoria, uma commodity. Tais aspectos são pouco difundidos e problematizados em trabalhos de Educação Ambiental formal e não formal, perdendo um significativo 
canal de veiculação e questionamento dessa realidade

A respeito deste assunto se ocupa o presente artigo. Uma vez que a água é base para a manutenção do sistema agroindustrial, as discussões que se deseja evidenciar estão circunscritas à produção agropecuária - mais especificamente, à produção de aves, suínos e leite -, e o potencial de seu uso como material de Educação Ambiental nas escolas de Francisco Beltrão, sobretudo, com os filhos de produtores agropecuários.

0 exclusivo benefício econômico de determinados setores da sociedade em contrapartida aos impactos ambientais ocasionados à maioria da população, fomenta o desejo de ampliar a visibilidade e a discussão a respeito do antagonismo de interesses inseridos nesta relação. Ao dar potência à análise crítica desta destinação da água, assim como dos ônus e bônus advindos dela, expecta-se o surgimento de exigências de contrapartidas que auxiliem na proteção e manutenção das fontes de água permanentemente.

A base de dados refere-se a produção de aves, suínos e leite no município de Francisco Beltrão no período de 2015 a 2016 da Secretaria de Abastecimento do Estado do Paraná - SEAB/COAB e IBGE.

\section{0 cálculo do consumo de água do setor agropecuário}

Grande parte do referencial metodológico utilizado tanto para a realização do cálculo do consumo de água quanto da pegada hídrica ou demanda hídrica do setor agropecuário é fornecido por Palhares $(2005,2011,2012,2013,2016)$, que esclarece:

Atualmente, várias escolas científicas realizam cálculos de pegada hídrica, mas com premissas diferentes. Entre elas se destacam o método holandês (Water Footprint Network) e o de análise de ciclo de vida. Em 2014, a Organização Internacional para Normalização (ISO) editou a ISO 14046, que estabelece os princípios e os requerimentos para o cálculo da pegada hídrica, seguindo o método de análise de ciclo de vida (PALHARES, 2016, p. 13).

Apesar de ser apontado como um importante elemento de gestão dos recursos hídricos por Palhares (2016), a aplicação do cálculo da pegada hídrica no Brasil apresenta, segundo o autor alguns elementos de limitação, dentre os quais cita que, embora normatizados os cálculos para a realização da estimativa da pegada hídrica de um setor, ou a água virtual contida em um determinado produto, não é aconselhável a realização de generalizações globais pois cada região e cada produto possui características específicas que devem ser consideradas, a menos que sejam produzidos em sistemas semelhantes e dentro das mesmas fronteiras de cálculos ${ }^{1}$.

Para Wood e Lenzen (2003), os cálculos de pegada (ecológica, carbono, hídrica, nitrogênio etc.) apresentam como vantagem a facilidade para sensibilização do público, servindo como uma ferramenta de educação ambiental que é relativamente fácil de calcular, compreender e comunicar. Segundo Stoeglehner e Narodoslawsky (2009), esses novos indicadores não se permitem a sensibilização, mas também servem de parâmetro para o planejamento e a tomada de decisão, além de considerarem a limitação da disponibilidade dos serviços ambientais (PALHARES, 2016, p. 12).

De acordo com Hoekstra et al. (2011), existe uma grande amplitude de aplicação do cálculo,

\footnotetext{
${ }^{1}$ A fronteira de cálculo se refere à delimitação espacial utilizada para assinalar a área onde se está realizando a estimativa. Pode ser aplicada em métricas gerais para indicar áreas com características físicas (de solos, precipitação, vegetação, etc.) análogos.
} 
que pode ser do produto, de uma empresa, cidade, país ou de todo o globo. 0 desenvolvimento dessa métrica por meio de cadeias produtivas favorece a não sobreposição de valores sobre os processos existentes em cada etapa da produção. No que tange à unidade de medida utilizada para o cálculo, também há grande abrangência ${ }^{2}$, e o impacto que a pegada tenha está diretamente relacionada a disponibilidade de água do local de onde é retirada. As etapas mais comuns na produção animal é o registro da água envolvida na produção do alimento, na dessedentação e na limpeza das instalações (HOEKSTRA et al., 2011).

De acordo com Palhares (2011, 2012), embora não tenha a pretensão de representar com exatidão a realidade, o cálculo proposto indica uma propensão para determinada situação de equilíbrio ou desequilíbrio ambiental. Por esta razão, pode ser utilizado como referência para tomada de decisões em relação a gestão ambiental da produção.

0 atributo destacado nesta metodologia, portanto, não é a exatidão, mas a capacidade de indicar a concentração da exploração da água em benefício de poucos, bem como a centralização de proveitos econômicos advindos das relações comerciais direcionadas por setores específicos com o argumento de produzir alimento para muitos.

\section{a)- Referência Adotada para o Cálculo da Pegada Hídrica da Produção de Aves}

O valor indicado por Palhares (2012) será adotado para o cálculo realizado na região Sudoeste do Paraná e no município de Francisco Beltrão. Registra-se, portanto, o montante de 4.325 litros de água por kg da carne de ave como referência para o presente estudo. Consideraram-se lotes mistos, cujo abate acontece em 42 dias, e o peso final de cada ave é, em média, de 2,652 kg. Significa dizer que as aves, contabilizadas em cabeças nos dados do IBGE, serão convertidas em quilogramas para a métrica da pegada hídrica do plantel.

\section{b) - Referência Adotada para o Cálculo da Pegada Hídrica da Produção de Suínos}

Será utilizada como referência para os cálculos deste estudo, a pegada hídrica dos suínos produzidos no estado do Paraná no ano de 2008 que, segundo Palhares (2011), foi de 1,1 trilhão de litros para toda a produção. Neste mesmo ano, o plantel paranaense foi, segundo IBGE, de 4.618.377 de cabeças.

A pegada hídrica de cada suíno produzido neste ano foi de 235.823 .537 (235,8 milhões) de litros por cabeça. Considerando que cada suíno, ao ser abatido, possui em média 110Kg (BERTOL et al., 2001), a pegada hídrica para cada quilograma de carne de suíno produzido no ano de 2008 foi de 2.143 litros/kg carne.

De acordo com Palhares (2016) os estudos demonstram que existe um equívoco quando a gestão e as políticas ambientais demonstram preocupação com a quantidade de água consumida na dessedentação e limpeza das instalações, uma vez que a maioria predominante da pegada hídrica da produção de suínos advém da produção dos grãos que são a base para a alimentação destes animais. A este respeito, o autor exorta a mudança de visão para que, ao invés de focar na unidade de produção, busque-se compreendê-la dentro da cadeia produtiva a qual pertence. Propõe a realização de zoneamento ecológico-econômico ${ }^{3}$ que oriente a expansão da produção de grãos e suínos no território, de acordo com a decisão dos comitês de bacias hidrográficas, e um plano de gestão integrado.

\footnotetext{
2 Para a definição da unidade de medida utilizada para o cálculo é possível grande diversidade, tendo sido exemplo de Hoekstra et al. (2011): metros cúbicos; toneladas de produtos; hectare de terra cultivada; unidade de moeda, dentre outras. ${ }^{3} 0$ Decreto № 4.297, de 10 de julho de 2002 define Zoneamento ecológico - econômico como: "... instrumento de organização do território..." que "... estabelece medidas e padrões de proteção ambiental destinados a assegurar a qualidade ambiental, dos recursos hídricos e do solo e a conservação da biodiversidade, garantindo o desenvolvimento sustentável e a melhoria das condições de vida da população" (Art. 2 Decreto 4.297/2002).
} 


\section{c) - Referência Adotada para o Cálculo da Pegada Hídrica da Produção de Leite}

É oportuno salientar que os dados aqui apresentados e considerados como referência para o cálculo da região Sudoeste do Paraná e município de Francisco Beltrão, se referem-se ao consumo de água/dia, ou apenas ao consumo de água para a produção de leite e não todo o consumo de água necessário para o cálculo da pegada hídrica referente à alimentação, limpeza e dessedentação de cada animal.

Dadas as características dos dados obtidos junto ao IBGE que são mensurados em litros de leites produzidos, considerou-se pertinente a indicação neste caso apenas da quantidade de água estimada para a produção de leite sem a mensuração de outros fatores. 0 valor adotado para a realização do cálculo para a região SO do PR e Francisco Beltrão será de 4 litros de água para cada litro de leite, seguindo indicação de Campos (2001).

\section{Totais de consumo de água para aves, suínos e leite no município de Francisco Beltrão e seu uso para educação ambiental}

A partir dos dados disponibilizados pelo IBGE (2015) e as referências para o cálculo da água consumida em cada produção, realizou-se a estimativa da água gasta no Brasil, Macroregião Sul, Paraná, Sudoeste do Paraná e Francisco Beltrão.

TABELA 1 - CONSUMO DE ÁGUA PARA A PRODUCÃO TOTAL DE LEITE, SUÍNOS E AVES

\begin{tabular}{|c|c|c|c|c|}
\hline \multicolumn{5}{|c|}{ VALORES TOTAIS DA PRODUÇÃO LEITE, SUÍNOS E AVES } \\
\hline Brasil & Sul & Paraná & SO do PR & Fco. Beltrão \\
\hline 24.930 .146 .579 .814 & 11.674 .910 .282 .199 & 5.417 .653 .132 .770 & 696.223 .003 .484 & 61.405 .509 .830 \\
\hline $100 \%$ & $100 \%$ & $100 \%$ & $100 \%$ & $100 \%$ \\
\hline \multicolumn{4}{|c|}{ PERCENTUAL DO CONSUMO DA ÁGUA POR SETOR DE PRODUÇ̃̃o DE AVES } \\
\hline $61,28 \%$ & $59,43 \%$ & $68,60 \%$ & $72,69 \%$ & $60,61 \%$ \\
\hline PERCENTUAL DO CONSUMO DA ÁGUA POR SETOR DE PRODUÇÃO DE SUÍNOS \\
\hline $38,15 \%$ & $40,14 \%$ & $31,06 \%$ & $26,67 \%$ & $38,93 \%$ \\
\hline \multicolumn{2}{|c|}{ PERCENTUAL DO CONSUMO DA ÁGUA POR SETOR DE PRODUÇÃo DE LEITE } \\
\hline $0,57 \%$ & $0,43 \%$ & $0,34 \%$ & $0,64 \%$ & $0,46 \%$ \\
\hline
\end{tabular}

Fonte: IBGE, 2015. Nota: Efetivo do rebanho em 31/12/2015.

Elaboração: LEME, R. B. (2017).

O Brasil consome, aproximadamente 25 trilhões de litros de água com a produção de leite, suínos e aves. Deste volume 61\% é destinado exclusivamente à produção de aves. A atividade de suinocultura é expressiva no cálculo da água consumida, como pode ser observado na tabela, entretanto, apenas $0,56 \%$ vincula-se à produção de leite.

Quanto avaliação da quantidade de água diretamente vinculada a produção destes três setores na região Sudoeste do Paraná, verifica-se uma concentração ainda maior, no que tange à água destinada à produção de aves, que, na mesorregião, aproxima-se de $73 \%$, enquanto que o município de Francisco Beltrão destina $56 \%$ da água consumida nos três setores diretamente à produção de aves.

O município compensa o menor percentual de consumo na criação de aves por meio de valores mais expressivos na produção de suínos ( $36 \%$ da água consumida nos três setores). Este fator merece atenção, porque reforça a situação do município ainda muito atrelada à produção de suínos, o que pode tornar o uso da água, na ausência de gestão adequada, em duplo problema ambiental, uma vez que, além de extrair a água sem nenhum tipo de consideração pela externalidade ambiental promovida, ainda causa contaminação do solo e das águas superficiais e subterrâneas pela má destinação do efluente gerado pelos excrementos dos animais. 
Estes dados podem ser discutidos e apresentados como proposta de prática pedagógica em vários contextos, inclusive para educação ambiental. Apesar disso, a realidade local não tem sido objeto de discussão aprofundada e qualificada, sobretudo, no âmbito escolar. A Educação ambiental não tem alcançado a efetiva construção de uma racionalidade ambiental que leve a processos menos degradadores da natureza, por isso sugere-se o uso destes dados nas escolas do ensino fundamental e médio do município de Francisco Beltrão - PR.

Em detrimento do contínuo processo de inserção de atividades de cunho ambiental nas escolas pesquisadas, tais atividades têm demonstrado preocupações extremamente setorizadas e sem a perspectiva de interconexão com as demais perspectivas de transformação da realidade nos quais os alunos estão inseridos e que, por meio da formação ambiental realmente contextualizada, continuada e crítica, estes educandos poderiam alterar.

Verifica-se que as discussões relacionadas ao meio ambiente e a sua correlata "crise ambiental", não se colocam apenas enquanto questionamentos ao modo de produzir e consumir os recursos naturais, mas, sobretudo, sobre a necessidade de uma nova forma de pensar esta relação, favorecendo a construção de uma sociedade na qual prevaleça a tolerância, a equidade, a pluralidade cultural e a democracia e o respeito a todas as formas de vida. Por este motivo, reforça-se a importância de inserir esta discussão junto as atividades de educação ambiental.

\section{Considerações Finais}

Questionar o consumo da água no setor agropecuário não exclui a admissão da importância deste setor na vida dos brasileiros e demais povos aos quais ele vincula. Ao contrário, implica em dar maior visibilidade às variáveis inseridas nesta questão que não é, nem pode ser considerada de forma linear e maniqueísta, mas, de forma complexa, indicar modos como os diferentes grupos da sociedade se apropriam dos elementos naturais transformando-os em recursos e, por meio da matriz de produção e consumo escolhida e estimulada provocam os impactos disseminados para toda a sociedade. Significa ainda ratificar que a crise ambiental não tem origem espontânea e a-social longe disso, é produzida em grande parte por segmentos bastante definidos da sociedade que se utilizam de ideologias e constroem territórios próprios para circulação e definição de uma razão socioeconômica. Todos estes aspectos devem ser abordados nos processos de discussão dos conteúdos de geografia e educação ambiental.

Muitos professores inseridos em projetos de caráter interdisciplinar concebem a educação ambiental enquanto uma obrigação a mais que lhe é imputada pela escola, sobrecarregando-o e dificultando o seu trabalho de "transmissão" de conteúdos escolares, que seria, a partir deste prisma, a sua principal obrigação.

Outros professores que fazem parte do universo que está sendo analisado, demonstram genuíno desejo de realizar os trabalhos de educação ambiental durante o seu processo educativo e, embora, uma parte significativa destes professores, também possuam uma visão bastante limitada da chamada crise ambiental e do modo como a educação ambiental pode contribuir na formação de atores sociais críticos, estes propõem-se continuamente a desenvolver o seu trabalho com persistência. É por este conjunto de profissionais, que se considerou válida o encaminhamento de propostas mais efetivas que proporcionassem dados efetivos que pudessem ser utilizados para discussão ambiental auxiliando na construção de novas relações entre a sociedade e a natureza.

Considerou-se que o não cumprimento do real desafio da educação ambiental enquanto implementação de prática interdisciplinar que auxilie na afirmação de valores e ações sociais e ecologicamente equilibradas e, sobretudo, que permita e estimule a realização de uma análise crítica a respeito do meio ambiente e da necessidade de que cada cidadão possui de protagonizar sua vida, não é efetivada, dentre outras razões, pela deficiência que os próprios professores de 
geografia tem em relação ao domínio e esclarecimento deste tema. Verificamos que dentre a maioria dos professores entrevistados, se mantêm uma visão simplista e individualista dos motivos que causam os problemas ambientais, gerando uma interpretação ingênua da função e os objetivos da educação ambiental.

A existência do fluxo internacional de água é algo positivo, pressupondo sua capacidade de equilibrar a má distribuição de água nas diferentes regiões do globo. A análise sistêmica ratifica presença de mobilizações de água por meio da aquisição de produtos de uma região rica em água para países e/ou regiões com escassez, diminuindo a pressão dos processos exploratórios de suas reservas limitadas de água e poupando o seu sistema de super exploração. Todavia, há necessidade de conhecimento a respeito dessa troca e a valorização de todos os elementos envolvidos neste processo.

A estimativa a respeito da quantidade de água consumida nas produções realizadas induz a ponderação sobre a simples quantificação da quantidade de água consumida e a realização de prognósticos em relação ao tempo de existência deste e de outros recursos naturais. Para além, reitera a necessidade de indeclinável esforço pela gestão integrada, o entendimento da dinâmica de funcionamento do sistema hidrológico e produtivo, compreendendo todos os sujeitos nele inseridos, bem como, a formação e qualificação de equipe técnica comprometida com a disseminação destas informações.

Compreender e decidir coletivamente qual a motivação que deve justificar o uso dos recursos e qual intensidade é mister, assim como identificar quem utiliza estes recursos e quais impactos ocasionados por este uso. Diferente do que tenta persuadir as empresas integradoras dos sistemas agroindustriais, tanto o produtor quanto o consumidor final devem estar continuamente prontos a questionarem não apenas os prazos de duração das provisões de recursos naturais mas, principalmente, a quem se destinam, qual o preço e os impactos gerados por esse uso. Não é um caminho fácil, mas o diálogo antecipado pode minimizar futuros conflitos que certamente ocorrerão, caso mecanismos mais claros de apropriação e uso não sejam estabelecidos prontamente.

\section{Referências}

BERTOL, Teresinha Marisa. LUDKE, Jorge Vítor. BELLAVER, Cláudio. Efeito do Peso do Suíno em Terminação ao Início da Restrição Alimentar sobre o Desempenho e a Qualidade da Carcaça. In: Rev. brasileira zootecnia, 30(2), p. 417- 424, 2001.

BRASIL. Decreto № 4.281, de 25 de Junho de 2002 - Regulamentando a Lei Federal 9795/1999 da Política Nacional de Educação Ambiental. Endereço eletrônico: http://www.planalto.gov.br/ccivil_03/decreto/2002/d4281.htm. Acessado em: 15/08/2016.

CAMPOS, Aloísio Torres de. Importância da água para bovinos de leite. In: EMBRAPA. Gado de Leite. Instrução técnica para o produtor de leite - outubro de 2001. Juiz de Fora, MG.

HOEKSTRA, Arjen Y. CHAPAGAIN, Ashok K. ALDAYA, Maite M. MEKONNEN Mesfin M. Manual de Avaliação da Pegada Hídrica -Estabelecendo o Padrão Global. Instituto de Conservação Ambiental The Nature Conservancy do Brasil - Water Footprint Network (WFN - Rede da Pegada Hídrica). 2011. Tradução: Secretaria do Meio Ambiente do Estado de São Paulo - SMASP e da Escola de Engenharia de São Carlos da Universidade de São Paulo - EESC-USP. 2011.

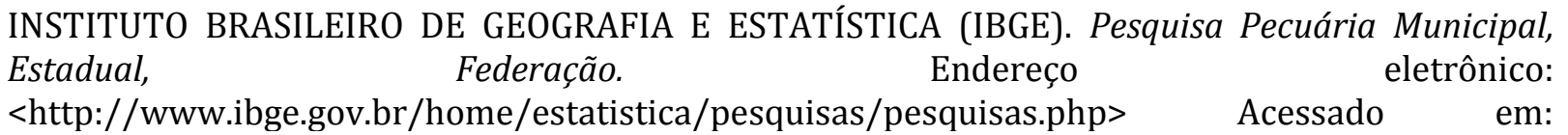
$02 / 07 / 2016$. 
OPOLSKI, Carolina Albertoni. A Educação Ambiental como Disciplina Escolar: Uma Análise da Disciplina de Educação Ambiental e Valorização do Espaço Local nos Estabelecimentos de Ensino do Município de Bom Jesus do Sul - PR. Universidade Estadual do Oeste do Paraná - Campus de Francisco Beltrão. 2016 (Dissertação de Mestrado).

PALHARES, Julio Cesar Pascale (organizador). Produção animal e recursos hídricos. São Carlos: Editora Cubo, 2016 (a).

PALHARES, Julio Cesar Pascale. Boas práticas hídricas na produção leiteira (versão 2). In: Comunicado Técnico 105. São Carlos: EMBRAPA. Setembro de 2016 (b).

PALHARES, Julio Cesar Pascale. Consumo de água na produção animal. In: Comunicado Técnico 102. São Carlos: EMBRAPA. Novembro de 2013. Endereço eletrônico: http://www.cppse.embrapa.br/sites/default/files/principal/publicacao/Comunicado102.pdf.

PALHARES, Julio Cesar Pascale. Pegada hídrica das aves abatidas no Brasil na década 2000-2010. In: 3º Seminário de Gestão Ambiental. Bento Gonçalves - RS, Brasil, 25 a 27 de Abril de 2012.

PALHARES, Julio Cesar Pascale. Pegada hídrica dos suínos abatidos nos Estados da Região CentroSul do Brasil. In: Acta Scientiarum - Animal Sciences. Maringá, v. 33, n. 3, p. 309-314, 2011.

SEGALA, Fernando José. O processo ensino de geografia a partir da hidrografia de Francisco Beltrão - PR. Francisco Beltrão: Unioeste, 2017. (Dissertação de Mestrado do Programa de Pós graduação em Geografia da Unioeste). 